\title{
Quality of life of patients after retropubic prostatectomy - Pre- and postoperative scores of the EORTC QLQ-C30 and QLQ-PR25
}

\author{
Peter Bach*, Tanja Döring, Andreas Gesenberg, Cornelia Möhring and Mark Goepel
}

\begin{abstract}
Background: Patients with newly diagnosed early stage prostate cancer (PCa) face a difficult choice of different treatment options with curative intention. They must consider both goals of optimising quantity and quality of life. The quality of life (QoL) is a psychometric outcome which is measured using validated questionnaires. Only few data are published concerning pre - and postoperative QoL.

Methods: This study investigated pre perative QoL of 185 patients who consecutively underwent open radical retropubic prostatectomy for organ-confined PCa to postoperative QoL of another 185 patients. The EORTC QLQC30, EORTC QLQPR25 module and 24 h ICS pad test were used (mean follow-up 28.6 months).

Results: The examined symptom scores of the EORTC QLQ-PR25 were on lowest level. In the dyspnoea symptom score differences of age emerged: the amount of patients who are short of breath rose significantly in older patients after surgery ( $p<0.05$ paired, two-tailed student's t-test).. Lastly, the urinary symptom score was found postal-therapeutically low; this fact was age independent. The results of sexual symptom score need to be taken into consideration, since prostatectomy resulted in a significant reduction of sexual activity independent of age. All functioning scales postoperatively reached high values without significant changes ( $p>0.05$ student's t-test), which implies a high QoL after surgery. A reliable and satisfying status of continence was found in our patients after retropubic prostatectomy. A high rate of patients (89.2\%) would choose retropubic prostatectomy again.

Conclusion: Retropubic prostatectomy represents a reliable and accepted procedure in the treatment of organconfined PCa. For the first time it could be shown that patients' QoL remained on a high level after retropubic prostatectomy. Nevertheless, the primary avoidance or postoperative therapy of erectile dysfunction should be in the focus of surgeons.
\end{abstract}

\section{Background}

Prostate cancer $(\mathrm{PCa})$ is the most common malignancy in men worldwide and is actually detected as localized disease in most patients. Diagnosis and therapy of $\mathrm{PCa}$ has long-ranging consequences for patient's further life. Patients with newly diagnosed early stage prostate cancer face a difficult choice of different treatment options with curative intention, and they must consider both goals of optimising quantity and quality of life. Radical prostatectomy is regarded as a standard surgical treatment in organ-confined $\mathrm{PCa}$ and may be performed in a

\footnotetext{
* Correspondence: bach@klinikum-niederberg.de

* Correspondence: bach@klinikum-niederberg.de University of Duisburg-Essen, Germany
} University of Duisburg-Essen, Germany

retropubic, perineal, laparoscopic or robotic-assisted way. Radiotherapy is established as a non-surgical approach in the curative treatment of localized PCa in its variations of external beam radiation, brachytherapy and permanent seed implantation. Recently research efforts have been made to sharply focus on showing and measuring quality of life outcomes together with more traditional end points of survival and disease-free status [1-4].

Despite advances in surgical techniques, the most common adverse consequences of radical prostatectomy continue to be urinary incontinence, erectile dysfunction and anastomic stricture [3,5]. QoL is a psychometric outcome which is measured using validated 
questionnaires. In our study the EORTC QLQ-C30 and EORTC QLQ- PR25 module [6] were used.

\section{Methods}

The main aim of this study was to compare QoL before and after radical prostatectomy. Until today it remains unclear whether radical prostatectomy leads to measurable postoperative morbidity and therefore influences QoL. Validated pretherapeutical QoL scores are still missing. However, this data is needed to help patients choosing between different therapeutic surgical and also non-surgical options. In addition, additional and different surgical approaches have been developed during the last years (laparoscopic and robotic-assisted laparoscopic surgery), which seem to lead to comparative oncological results with possible lower change of QoL. Thus QoL may be a major factor in comparing different surgical procedures [3].

\subsection{Study design: Prospective clinical trial}

On the day before radical retropubic prostatectomy the EORTC QLQ-C30 and EORTC QLQ-PR25 module was filled out by patients $(\mathrm{n}=185)$ for preoperative QoL data (2006 to 2008). A matched-pairs analysis was performed regarding age. At least 6 months after surgery another 185 patients (who were matched-pairs regarding age) were subjected to the EORTC QLQ-C30 and EORTC QLQ-PR25 module for postoperative QoL scores and underwent a $24 \mathrm{~h}$ ICS pad test (mean followup 28.6 months) (2002 to 2006). During hospital stay after surgery and catheter removal a $24 \mathrm{~h}$ ICS pad test had been performed before [6-8]. For the match-pairs analysis no disease characteristics or nerve-sparing procedures were used. Ethical approval was asked at University of Essen during 2005.

\subsection{Patients}

This study investigated two groups of 185 patients each who consecutively underwent open radical retropubic prostatectomy at the Department of Urology of Klinikum Niederberg, Velbert, Germany. Three surgeons performed ascending retropubic prostatectomy including regional lymphadenectomy of the regions arteria iliaca externa, interna, and obturatoric area.

Average patient age was 66.5 years (range 48 to $79 \mathrm{y}$ ). 134 patients $(72.4 \%)$ were younger than 70 years, and 51 $(27.6 \%)$ older than 70 years at the time of surgery. In guidelines of german association of urology (DGU) in 2004 there has been a restricted recommendation for prostatectomy in patients 70 years or older. Therefore all datas were analyzed in subgroups younger and older than 70 years. Since 2006 the QLQ-C30 plus QLQ-PR25 module was assessed for our patients before prostatectomy.
In order to perform a comparison between pre- and postoperative QoL data, a matched-pairs analysis regarding age was performed between preoperative data from 185 patients who underwent surgery from June 2006 to June 2008 to postoperative data from 185 patients from 2002 to 2006.

The amount of nerve-sparing prostatectomy was different in both groups $(32,4 \%(60 / 185)$ to $36,7 \%(65 /$ 185)).

\subsection{Quality of life}

\subsubsection{Assessment of quality of life}

Prostate cancer-specific EORTC QLQ-PR25 module is available since mid-2006. We carried out a matchedpairs analysis in our presurgical population. A matchedpairs analysis is a statistical procedure assigning a control person to every patient. In this study the matched patient was chosen with the same age on the day before radical prostatectomy.

EORTC QLQ-PR25 questionnaire was performed on day before surgery and during follow-up at a minimum of 6 months after surgery (mean 28.6 months).

\subsubsection{EORTC QLQ-C30}

EORTC QLQ-C30 is a validated questionnaire for QoL in patients suffering from malignancy $[8,9]$. EORTC QLQ-C30 measures QoL and general status of health in a score called Global Health Status (GHS), allowing values in a range from 0 to 100 . Therefore, high scores represent a high QoL and low scores a low one. Five functional scales measure body, role, emotional, cognitive and social function of patients. Again, a high value reflects high function of functional scales and low value shows low or disappointing function.

Additionally, the questionnaire includes three symptom scores (fatigue, emesis and pain) and six further single-item symptom scores (dyspnoea, insomnia, appetite loss, constipation, diarrhoea and financial difficulties) which may occur in PCa patients. All these scales and scores have four scoring possibilities, ranging from 1 (not at all) to 4 (very often). A high symptom score represents a large amount of symptoms. For better classification all scores and items are shown on scales from 0 to 100 [7].

In addition to the EORTC QLQ-C30 as a basic questionnaire few additional modules are published, which access different malignancies or states of disease. We used the PR 25 module which is avaibale since 2006. It was published in 2008 as a validated tool for PCa [6].

\subsubsection{EORTC QLQ-PR25 Module}

An additional questionnaire contains four symptom scales which are of main interest in evaluating QoL. These are symptoms concerning defacation, micturition, treatment and sexuality (bowel-, urinary-, treatmentrelated and sexual symptoms) [6]. 
Postoperative urinary symptom score is of main interest to surgeons because of its important role in patients' QoL. It is important to know that questions scoring for urinary symptoms are valuing urge incontinence more than stress incontinence. Stress incontinence after radical prostatectomy was evaluated by ICS $24 \mathrm{~h}$ pad test (see 2.4). Sexual symptom scores were not comparable, because of a different amount of a nerve-sparing prostatectomy in both groups (data not shown).

\subsection{International Continence Society $\mathbf{2 4}$ hours pad test}

Patients were instructed to weigh dry pads, collect wet pads and weigh wet pads after $24 \mathrm{~h}$. This test was performed under daily life conditions [10].

ICS $24 \mathrm{~h}$ pad test was performed within 12.2 days after surgery. Late continence was assessed by another $24 \mathrm{~h}$ pad test 6 or more months after surgery. Patients reporting pad usage were followed up to 28.6 months.

\subsection{Self-created questionnaire}

Patients were asked another four questions in addition to validated questionnaires which could be answered by "Yes" or "No". These answers were used for assessing the quality of treatment and the degree of patients' satisfaction concerning treatment (median follow-up 28.6 months). For further details see Additional file 1.

\subsection{Statistics}

Microsoft Excel $2002^{\mathrm{TM}}$ was used for surveying data and performing matched pairs analyses. Significance was calculated by parametric and paired t-tests (Wilcoxon signed rank test and paired ANOVA followed by Bonferroni's multiple comparison test) using GraphPad Prism $^{\mathrm{TM}}$. A $\mathrm{p}<0.05$ was regarded as significant.

\section{Results}

\subsection{Quality of Life}

\subsubsection{Global Health Status}

The patients' state of health and quality of life assessed by self-evaluation is regarded as the global health status (GHS). Patients older than 70 years showed acceptable value for GHS following surgery of 69.3 with a significant reduction to preoperative GHS (73.5; p $<0.05$, Student's t-test). A significant reduction of GHS concerning all patients was not found ( $\mathrm{p}>0.05$, Student's t-test). For further details see table 1 .

3.1.1.1 Preoperative global health status A total of $104 / 185$ patients $(56.8 \%)$ showed state of health as good to excellent one day before surgery $(56.9 \%>70$ years vs. $56.0 \% \leq 70$ years). A bad to poor state of health was described by three patients (1.6\%). $48.1 \%$ patients showed QoL good to excellent $(48.1 \%>70$ years vs. $48.5 \% \leq 70$ years; $p>0.05$, Student's t-test), $6 \%$ reported bad to poor quality of life before surgery $(5.9 \%>70$
Table 1 Global health status

\begin{tabular}{cccc}
\hline global health status & \multicolumn{3}{c}{ Patients } \\
& all & $\leq \mathbf{7 0}$ years & $>\mathbf{7 0}$ years \\
\hline preoperative & $73.8 \pm 22.6$ & $73.8 \pm 22.5$ & $73.5 \pm 25.2$ \\
postoperative & $69.4 \pm 17.1$ & $69.7 \pm 16.0$ & $69.3 \pm 19.8^{*}$ \\
\hline
\end{tabular}

Preoperative and postoperative global health status is shown as mean \pm standard error of the mean of all patients and patients' $\leq 70$ years and $>70$ years (matched-pairs analysis). ${ }^{*} p<0.05$ vs. preoperative value, paired, twotailed student's t-test

years vs. $6 \% \leq 70$ years; $p>0.05)$. No significant difference in preoperative global health status and quality of life was seen between age groups as assessed by student's t-test ( $\mathrm{p}>0.05)$.

3.1.1.2 Postoperative global health status 58.4\% (108/ 185) patients showed state of health as good to excellent 6 months after surgery $(59.7 \%>70$ years vs. $55.0 \% \leq 70$ years; $\mathrm{p}>0.05$ student's t-test). $32.5 \%$ of patients reported good to excellent quality of life postoperatively $(23.5 \%>$ 70 years vs. $35.9 \% \leq 70$ years; $\mathrm{p}>0.05$ student's t-test).

Regardless of age six patients (3.2\%) reported bad to poor quality of life at least six months following surgery ( $\mathrm{p}>0.05$ student's t-test).

\subsubsection{Functioning scales of EORTC QLQ-PR25}

Cognitive and social functioning scales pointed a high level of functioning (>90) before surgery with significant changes (all $\mathrm{p}<0.05$ Student's t-test) following prostatectomy. Emotional functioning scale showed a low level one day before prostatectomy (78.2) and a significant higher score (90.4) during follow-up independent of age (all $\mathrm{p}<0.05$ Student's t-test).

Preoperative sexual functioning scale represented the lowest function level (55.7). There was no significant difference after treatment ( $p>0.05$ student's t-test). For further details see table 2 .

\section{Table 2 Functioning scales of EORTC QLQ C30}

\begin{tabular}{|c|c|c|c|}
\hline \multirow[t]{2}{*}{ functioning scales } & \multicolumn{3}{|c|}{ patients } \\
\hline & all & $\leq 70$ years & $>70$ years \\
\hline pre physical functioning & $93.2 \pm 9.9$ & $93.5 \pm 9.1$ & $92.4 \pm 11.7$ \\
\hline post physical functioning & $94.4 \pm 11.6$ & $94.7 \pm 10.0$ & $93.5 \pm 15.0$ \\
\hline pre role functioning & $92.2 \pm 13.4$ & $92.9 \pm 12.8$ & \\
\hline post role functioning & $91.4 \pm 18.6$ & $92.5 \pm 16.9$ & $88.9 \pm 22.1$ \\
\hline pre emotional functioning & $78.2 \pm 22.7$ & $76.4 \pm 24.4$ & $80.9 \pm 18.9$ \\
\hline post emotional functioning & $91.4^{*} \pm 14.3$ & $91.2^{*} \pm 15.1$ & $90.4^{*} \pm 15.2$ \\
\hline pre cognitive functioning & $91.6 \pm 16.7$ & $92.2 \pm 15.5$ & $90.5 \pm 17.2$ \\
\hline post cognitive functioning & $94.6=$ & 95.2 & 14.8 \\
\hline pre social functioning & $90.2 \pm 14.4$ & $90.2 \pm 14.4$ & $89.9 \pm 14.4$ \\
\hline post social functioning & $91.5 \pm 19.4$ & $91.2 \pm 19.9$ & $90.5 \pm 20.7$ \\
\hline pre sexual functioning & $55.7 \pm 32.3$ & $54.3 \pm 31.7$ & $59.0 \pm 33.2$ \\
\hline post sexual functioning & $56.8 \pm 30.0$ & $55.5 \pm 30.5$ & $59.6 \pm 28.5$ \\
\hline
\end{tabular}

Pre (pre) - and postoperative (post) data are shown (mean \pm standard error of the mean) for physical, emotional, role, cognitive, social and sexual

functioning. $n=185$ for all scales paired, two-tailed student's t-test * $p<0.05$ vs. preoperative values 


\subsubsection{Symptom scores of EORTC QLQ-PR25}

Patients pre- and postoperatively scored low values represented few or a total lack of symptoms. Only the score for sexual symptoms showed higher values. For further details see Table 3.

3.1.3.1 Dyspnoea symptom score The dyspnoea symptom score rised from a low level preoperative to higher postoperative levels for the whole study population (from $7.8 \pm 16.5$ (mean \pm s.e.m.) to $15.3 \pm 23$; p < 0.05 paired, two-tailed Student's t-test). Patients $>70$ years suffered from significant higher scores in postoperative analysis ( $\mathrm{p}<0.05$ student's t-test).

3.1.3.2 Insomnia symptom score Insomnia symptom score changed significantly from preoperative to postoperative population $(7.8 \pm 15.4(\mathrm{M} \pm \mathrm{SEM})$ to $15.5 \pm$ 25.6; $\mathrm{p}<0.05$ student's t-test).

3.1.3.3 Urinary Symptom Score Pre - and postoperative urinary symptom scores of all patients showed no significant difference ( $p>0.05$ student's t-test). A subgroup analysis of patients suffering from a high-grade incontinence ( $\mathrm{II}^{\circ}$ and higher; $\mathrm{n}=11$ ) showed an average GHS (70.3) ( $p>0,05$; student's t-test following Bonferroni's multiple comparison test).

3.1.3.4 Sexual Symptom Score Because of the different amount of patients underwent a procedure of nervesparing prostatectomy in both groups a valuable comparison of pre - and postoperative sexual symptom scores could not be performed.

A subgroup analysis found in the sexual active patients (52/185) a high QoL (73.4). In comparison to the whole postoperative population we found a significant difference ( $\mathrm{p}<0.08$; students $\mathrm{t}$-test). $78.8 \%(41 / 52)$ of the postoperative sexual active patients received a nerve-sparing procedure.

\subsection{Continence}

The status of continence resulting from ICS $24 \mathrm{~h}$ pad test was processed as a multivariate analysis to life age, blood loss and TNM stadium. A predictive factor for incontinence following prostatectomy could not be

Table 3 EORTC QLQ-PR25 Symptom scores

\begin{tabular}{|c|c|c|c|}
\hline symptom scores & all patients & patients $\leq 70$ years & patients $>70$ years \\
\hline preoperative fatigue & $7.5 \pm 12.6$ & $7.9 \pm 12.8$ & $6.1 \pm 11.7$ \\
\hline postoperative Fatigue & $6.4 \pm 13.7$ & $4.8 \pm 10.3$ & $10.2 \pm 19.4$ \\
\hline preoperative nausea \& vomiting & $1.00 \pm 4.0$ & $0.9 \pm 3.7$ & $1.3 \pm 4.5$ \\
\hline postoperative nausea \& vomiting & $1.00 \pm 5.8$ & $0.6 \pm 4.3$ & $2.0 \pm 8.5$ \\
\hline preoperative pain & $8.3 \pm 16.2$ & $6.8 \pm 13.7$ & $11.8 \pm 21.0$ \\
\hline postoperative pain & $9.0 \pm 16.7$ & $7.6 \pm 14.6$ & $12.4 \pm 20.6$ \\
\hline preoperative dyspnoea & $7.8 \pm 16.5$ & $7.2 \pm 15.4$ & $9.2 \pm 18.8$ \\
\hline postoperative dyspnoea & $15.3^{*} \pm 23.0$ & $13.7 \pm 20.9$ & $19.0^{*} \pm 27.4$ \\
\hline preoperative insomnia & $7.8 \pm 15.4$ & $7.7 \pm 15.2$ & $7.8 \pm 15.6$ \\
\hline postoperative insomnia & $15.5^{*} \pm 25.6$ & $16.7^{*} \pm 26.0$ & $11.8 \pm 23.6$ \\
\hline preoperative appetite loss & $4.6 \pm 11.5$ & $5.5 \pm 12.4$ & $2.0 \pm 7.8$ \\
\hline postoperative appetite loss & $3.1 \pm 15.1$ & $2.5 \pm 13.9$ & $4.6 \pm 17.5$ \\
\hline preoperative constipation & $5.8 \pm 12.7$ & $6.0 \pm 12.8$ & $5.2 \pm 12.1$ \\
\hline postoperative constipation & $6.4 \pm 18.2$ & $6.2 \pm 17.4$ & $6.5 \pm 19.8$ \\
\hline preoperative diarrhoea & $2.9 \pm 9.4$ & $2.7 \pm 9.2$ & $3.3 \pm 9.9$ \\
\hline postoperative diarrhoea & $2.7 \pm 11.5$ & $2.0 \pm 10.6$ & $4.6 \pm 13.2$ \\
\hline preoperative financial difficulties & $0.6 \pm 4.2$ & $0.8 \pm 4.9$ & $0.7 \pm 4.6$ \\
\hline postoperative financial difficulties & $1.6 \pm 8.7$ & $1.2 \pm 7.5$ & $3.3 \pm 11.9$ \\
\hline preoperative urinary symptoms & $14.1 \pm 15.1$ & $14.1 \pm 15.5$ & $13.7 \pm 15.0$ \\
\hline post urinary symptoms & $9.1 \pm 11.8$ & $9.8 \pm 12.2$ & $7.1 \pm 10.4$ \\
\hline preoperative bowel symptoms & $1.1 \pm 3.9$ & $1.0 \pm 3.2$ & $1.5 \pm 5.1$ \\
\hline postoperative bowel Symptoms & $2.3 \pm 7.3$ & $1.9 \pm 6.4$ & $3.1 \pm 9.0$ \\
\hline preoperative treatment-related symptoms & $8.1 \pm 8.8$ & $8.7 \pm 9.0$ & $6.2 \pm 7.5$ \\
\hline postoperative treatment-related symptoms & $11.5 \pm 10.6$ & $12.0 \pm 10.8$ & $10.1 \pm 9.5$ \\
\hline preoperative sexual symptoms** & $32.2 \pm 30.8$ & $32.6 \pm 32.1$ & $29.2 \pm 26.3$ \\
\hline postoperative sexual symptoms*** & $45.3 \pm 20.4$ & $48.3 \pm 19.7$ & $35.2 \pm 19.7$ \\
\hline
\end{tabular}

Pre - and postoperative values of all sympotm scores (mean \pm standard error of the mean; $\mathrm{n}=185$ ) as a match-pairs analysis, paired, two-tailed student's $\mathrm{t}$-test * $p<0.05$ vs. preoperative values

** $\mathrm{n}=127$ patients

*** $\mathrm{n}=52$ patients 
found. Due to the relatively low number of patients, a valid analysis of continence concerning histological classification could not be performed.

\subsubsection{Status of early continence}

Early ICS $24 \mathrm{~h}$ pad test reported $69.2 \%(\mathrm{n}=128)$ of all patients as primary continent. The number was not significantly different with respect to patient's age (older than 70 y: $70.6 \%$ vs. younger than 70 y $60.7 \%$; $p>0.5$, student's ttest following Bonferroni's multiple comparison test).

In 16 patients with high grade incontinence $\left(\mathrm{II}^{\circ}-\mathrm{III}^{\circ}\right)$ no significant difference was found concerning patient's age (older than 70 y: $7.8 \%$ vs. younger than 70 y $8.9 \%$; p $>0.5$ student's t-test following Bonferroni's multiple comparison test). For further details see table 4 .

\subsubsection{Status of late continence}

163 patients $(88.1 \%)$ reported to use no pad or only a safety pad during follow-up (28.6 months); this outcome was independent of age (older than 70 y: $80.4 \%$ vs. younger than $70 \mathrm{y}: 91.0 \%$; $\mathrm{p}>0.5$ student's t-test following Bonferroni's multiple comparison test). For further details see table 5 .

\subsection{Surgical results}

Our study was performed in a typical population undergoing radical prostatectomy. For further details see table 6 .

\subsection{Satisfaction questionnaire}

Nearly all patients (89.2\%) would choose the surgical approach again when asked 6 months after retropubic prostatectomy. A similar large proportion of patients felt well informed about prostate cancer (86.5\%). The cosmetic outcome was regarded as satisfying by about $88.1 \%$ of all patients. For these three questions no significant difference was found between age groups ( $p>0.05$ student's t.-test). For further details see table 7.

The number of patients who underwent therapy of erectile dysfunction was small (24.9\%). In older patients, even a smaller amount of patients received treatment (13.7\%, p $<0.05$ vs. younger patients, two-tailed student's t-test).

\section{Discussion}

Therapy decisions may lead to cancer treatment success, but may also be followed by typical complications.
Patients' satisfaction is influenced by postoperative QoL as well as by postoperative morbidity. Critical evaluation of treatment pathways is essential to reach new clarifications and better therapy decisions for patients and therapeutic options in the near future.

Recent publications regarding localized prostate cancer published by radiotherapeutics show a careful and precise assessment of QoL [5,11-13].

The first studies were published assessing QoL using the EORTC QLQ-C30 including the prostate specific QLQ-PR25 module in 2008. The PR25 module was validated in October 2008 by Aaronson and colleagues [6]. Only few studies contain data from PR25, and here data concerning open operative therapy and preoperative status are still missing $[14,15]$.

Therefore investigation of QoL in postoperative patients is most important, because prospective randomized trials comparing different therapy pathways (e.g., operation vs. radiotherapy) are still missing. Our study investigates a patient population before and after radical retropubic prostatectomy. This data is comparable to published populations respective to age and state of localized disease [16].

Interpretation of this data in a scientific context still causes difficultly because to date only a few published studies are available with data from the EORTC QLQPR25. Quality of life within a retrospective analysis may rise with the number of included patients, because patients with good postoperative results more often take part in questionnaires and therefore positively influence the results. Moreover, patients with worst outcome may have died within the time of follow-up and hence unavailable to answer a survey as well. In our study records of $83 \%$ of all included patients were analyzed, which is comparable to similar studies [17].

\subsection{Quality of life}

A possible decrease of Quality of life (QoL) after RRP patients was of growing interest in recent retrospective analyses [14]. Post-therapeutic morbidity and changes of QoL are important to regard efficient cost/use analysis of cancer therapy pathways. Pre- and post-surgical state of QoL in our patients contributes therefore to the

Table 4 Results of early continence

\begin{tabular}{lcccccc}
\hline & \multicolumn{2}{c}{ continence } & $\mathbf{I}^{\circ}-\boldsymbol{I I}^{\circ}$ & $\mathbf{I}^{\circ}$ & $\mathbf{I}^{\circ}-\boldsymbol{I I I}^{\circ}$ & $\mathbf{I I}^{\circ}$ \\
\hline Pads/24 $\mathrm{h}$ & No & Safety pad & $1-2$ & $2-4$ & $5-8$ & $>8$ \\
ICS Pad Test (ml) & 0 & $0-2$ & $2-10$ & $10-50$ & $>50$ & no micturition \\
All patients (\%) & 18.9 & 50.3 & 15.1 & 7.0 & 4.3 & 4.3 \\
Patients $\leq 70$ years (\%) & 20.2 & 48.5 & 14.2 & 8.2 & 3.7 & 5.2 \\
Patients > 70 years (\%) & 15.7 & 54.9 & 17.7 & 3.9 & 5.9 & 1.9 \\
\hline
\end{tabular}

Results of the early continence in ICS $24 \mathrm{~h}$ pad test following radical retropubic prostatectomy (follow-up 12.2 days). A loss of 0-2 ml urine was regarded as social continent $(n=185 ; p>0.5$ between young and old patients, student's t-test). 
Table 5 Results of late continence

\begin{tabular}{|c|c|c|c|c|c|c|}
\hline & \multicolumn{2}{|c|}{ continence } & \multirow{2}{*}{$\begin{array}{l}1^{\circ}-1 I^{\circ} \\
1-2\end{array}$} & \multirow{2}{*}{$\begin{array}{c}\mathrm{II}^{\circ} \\
2-4\end{array}$} & \multirow{2}{*}{$\begin{array}{c}1 I^{\circ}-11 I^{\circ} \\
5-8\end{array}$} & \multirow{2}{*}{$\begin{array}{c}\mathrm{III}^{\circ} \\
>8\end{array}$} \\
\hline & no pads & a safety pad & & & & \\
\hline ICS pad test (ml) & 0 & $0-2$ & $2-10$ & $10-50$ & $>50$ & no micturition \\
\hline All patients (\%) & 81.6 & 6.5 & 5.9 & 4.4 & 1.1 & 0.5 \\
\hline Patients $\leq 70$ years $(\%)$ & 85.1 & 5.9 & 5.2 & 2.2 & 0.8 & 0.8 \\
\hline Patients > 70 years (\%) & 72.6 & 7.8 & 7.8 & 9.8 & 2.0 & 0.0 \\
\hline
\end{tabular}

Results of the late ICS $24 \mathrm{~h}$ pad test following open retropubic radical prostatectomy (follow-up $28.6 \mathrm{months}$ ). A loss of $0-2 \mathrm{ml}$ urine was regarded as social continent $(n=185)$. Incontinence $>I^{\circ}$ showed a significant difference and was dependent of age $(p<0.02$ student's t-test).

quality assurance of surgery in our department. Therefore it was focused on QoL before and after surgery.

\subsubsection{Global Health Status}

The global health status (GHS) is a point value out of the self-assessment of the QoL of a patient. The values of GHS of patients suffering from prostate cancer in our study population are in line with published data worldwide $[11,14]$. A GHS of 76.3 points is described by Arredondo in 2006 that changed to 74.1 points on average two years after radical retropubic prostatectomy. In our population, the median GHS started on 73.8 points and ended up at 69.4 points. It is noteworthy that Arredondo reported about a larger (854 patients) and, on average, younger population [18], and younger patients may subjectively experience a greater decrease in QoL because of their greater overall wellbeing.

The decrease of QoL after surgery was significant only in patients older than 70 years. Here the results differ from data of Arredondo, which showed no significant change in QoL in different age groups. But, as mentioned, his population was younger on average at the time of surgery, and our patients older than 70 were twice as frequent compared to Arredondos study (27\% vs. $13 \%)$. Radical prostatectomy should be discussed carefully with patients older than 70 , mentioning the possibility of greater-than-average QoL loss.

However, different conclusions concerning age and QoL were drawn in history: For example. Jayadevappa

\section{Table 6 Surgical results}

\begin{tabular}{ccc}
\hline Item & Median & Range \\
\hline Time of operation & $116 \mathrm{~min}$ & 50 to $360 \mathrm{~min}$ \\
Follow-up & $28.6 \mathrm{months}$ & 6 to $62 \mathrm{months}$ \\
PSA level & $9.1 \mathrm{ng} / \mathrm{ml}$ & 0.3 to $59.0 \mathrm{ng} / \mathrm{ml}$ \\
Gleason Sum & 6.3 & 4 to 9 \\
No. of lymph nodes & 11 & 4 to 24 \\
40-day survival & $100 \%$ & - \\
Hospital stay & 13.2 days & 7 to 21 days \\
& Positive margins $\mathbf{R} 1$ & \\
Total & & $69 / 185(30.9 \%)$ \\
pT2 & & $15(10.6 \%)$ \\
pT3 & & $95(100 \%)$ \\
pT4 & &
\end{tabular}

showed that age of patients has no influence on QoL following prostatectomy [19]: 115 patients older than 65 years underwent either a radical prostatectomy or radiotherapy. After 3, 6 and 12 months, no reduction of the QoL could be found. Authors concluded age not determining the choice of treatment in prostate cancer. Our data show no significant reduction of Qol by a radical prostatectomy in our study population as well. Published data of GHS are on similar level to GHS scores of our patients [11].

\subsubsection{Functioning scales of EORTC QLQ-C30}

RRP did not affect functioning scales of the EORTC QLQ-C30. There was no significant change between pre- and postal-surgical values and between younger and older patients. The only exception occurred in the emotional functioning scale. Preoperative concerns were reported by all patients independent from age. After surgery this scale significantly improved by about twelve points (78.2 to 91.4). Emotional functioning scales in published studies shows similar data [3]. Lips published comparable data concerning quality of life after radiotherapy. A significant rise of the emotional functioning scale six months after radiotherapy was seen there, which is in the same range observed by us. Successful coping strategies and temporal distance to the diagnosis may be responsible for restoration of emotional functioning. No significant change of other functional scales was observed by Lips 6 months after therapy. Also sexual functioning scale did not change after therapy independent from surgical or radiotherapy $[3,11]$.

\subsubsection{Symptom scores of EORTC QLQ-PR25}

Most symptom scores did not change after surgery. Only dyspnoea, insomnia, urinary and sexual symptom score showed significant changes, which will be discussed below. The data of Lips, Arredondo and Jayadevappa show similar results after therapy. Only bowel symptom score remained unchanged and increased significantly 6 months after radiotherapy $[11,18,19]$.

4.1.3.1 Dyspnoea symptom score In our data dyspnoea symptom score increased significantly from 7.8 to 15.3 points after surgery. In the older population this change was more predominant (9.2 to 19.0 pts). Each of our patients received an preoperative chest $x$-ray and none of these patients suffered postoperative from an 
Table 7 Satisfaction questionnaire

\begin{tabular}{|c|c|c|c|c|}
\hline \multicolumn{2}{|l|}{ Satisfaction questionnaire } & \multirow{2}{*}{$\begin{array}{c}\text { All patients } \\
89.2 \%\end{array}$} & \multirow{2}{*}{$\begin{array}{c}\text { Patients } \leq \mathbf{7 0} \text { years } \\
90.3 \%\end{array}$} & \multirow{2}{*}{$\begin{array}{c}\text { Patients }>\text { 70 Jahre } \\
86.3 \%\end{array}$} \\
\hline 1. Would you choose prostatectomy again? & Yes & & & \\
\hline & No & $10.8 \%$ & $9.7 \%$ & $13.7 \%$ \\
\hline \multirow{2}{*}{ 2. Do you feel well informed about prostate cancer? } & Yes & $86.5 \%$ & $85.8 \%$ & $88.2 \%$ \\
\hline & No & $13.5 \%$ & $14.2 \%$ & $11.8 \%$ \\
\hline \multirow[t]{2}{*}{ 3. Did you receive a therapy of erectile dysfunction? } & Yes & $24.9 \%$ & $29.1 \%$ & $13.7 \% *$ \\
\hline & No & $75.1 \%$ & $70.9 \%$ & $86.3 \%$ \\
\hline \multirow[t]{2}{*}{ 4. Are you satisfied by cosmetical outcome? } & Yes & $88.1 \%$ & $88.1 \%$ & $88.2 \%$ \\
\hline & No & $11.9 \%$ & $11.9 \%$ & $11.8 \%$ \\
\hline
\end{tabular}

Answers of 185 patients following prostatectomy during follow-up are shown. There are no significant differences between age groups ( $p>0.05$, student's-test) with the exception of erectile dysfunction therapy ( ${ }^{*} p<0.05$ vs. younger patients).

pulmonary embolism. But no further investigation were performed. Howeverwe found here a significant difference compared to published data. Lips could not detect any change in dyspnoe three years after therapy in a comparable study group concerning age and comorbidity [11]. Surgery could be responsible for this effect, because only small but significant changes (10 points) were noted. Increase of dyspnoea will influence QoL of cancer patients [20]. Patients suffering from pulmonal comorbidity need to be carefully informed.

4.1.3.2 Insomnia symptom score Compared to published data our study showed lower symptom scores concerning insomnia. In younger patients figures significantly increased after therapy.

4.1.3.3 Urinary Symptom Score 32\% of preoperative patients had medical treatment for bladder outlet obstruction. Questionaire dominates urge incontinence more than stress incontinence symptoms. Urinary symptom score after therapy decreased (9.1) below preoperative level (14.1). Even a higher incontinence resulting in higher urinary symptom score showed no significant reduction of QoL in our patients. Urinary symptom scores were similar to recent published data after radiotherapy (15 to 17, Lips 2008). Because PR25 could be converted only in 2008 into a phase IV module there is still a lack of validated data. Sacco et al. observed reduction of QoL by incontinence symptoms compared to age (a larger population with comparable age distribution was examined) $[11,21]$.

QoL was not limited by bladder symptoms in our patients' independent of age and of incontinence.

4.1.3.4 Sexual Symptom Score Sexual disability caused by non nerve-sparing prostatectomy leading to a reduction of QoL is known from many investigations [4]. High sexual symptom scores (45.3) were found in our post-surgical population. Here we found the highest values of all symptom scores in our investigation. The also preoperative high sexual symptom score increased after surgery. However, this was not statistically significant. But because of an amount of $36,7 \%$ nerve-sparing procedures in this population we could not draw a conclusion in general.

The amount of patients who gained sexual activity after a nerve-sparing prostatectomy is significant higher, therefore leading to a higher QoL in this subroup.

Comparing to patients after radiotherapy referring PR25 (Junius 2007; $\mathrm{n}=38$ ) a similar sexual symptom score (44) was noted. A possible explanation is antiandrogen medical therapy together with radiotherapy. Conclusively, significant reduction of the sexual symptom score was seen six months after therapy (to 17.2) [22]. Lips also saw a reduction of the sexual activity after radiotherapy and a significant rise of sexual symptom scores [11].

\subsection{Results of continence}

\subsubsection{Status of early and late continence}

$69.2 \%$ of all operated patients reached continence after 12 days after surgery, and $88.1 \%$ after about 28.6 months. These results are comparable with published data of large studies concerning continence after radical prostatectomy [21].

The short-term result of continence following open surgery ( 6 weeks after operation) is reported to be 18 $48 \%[23,24]$.

Published long time results of continence vary from $38 \%$ to $92 \%[16,21,25]$ Compared to these data, the status of early continence in our study seemed to be better and the status of late continence within average. One reason for this variance among others is a missing of a uniform definition of continence in different publications. Hence, a comparison of continence results is difficult and modestly reliable at best. Moreover, in the large studies cited here, the status of continence was mostly asked for and not raised objectively.

For example, the working group of McCammon determined status of continence of 199 patients after radical prostatectomy after 12 months. Post-prostatectomy incontinence in this study was defined by more than two self-reported incontinence episodes in 24 hours; 
however, a validation did not occur. $76.3 \%$ of the operated patients reported no pads, but only $38.2 \%$ indicated not to suffer from incontinence [25].

Evaluation of continence by a standardised test procedure (ICS) appears to be more authentic and reliable than a unique questioning. In our study, the ICS $24 \mathrm{~h}$ pad test shows no significant difference to the published data of other studies.

This represents a reliable and comparable status of continence in our patients after retropubic prostatectomy.

Loss of blood, body-mass index, age of the patient and state of disease are discussed as influencing state of continence. Sacco et al. could ascertain age, a non-nervesparing technique, and strictures of the anastomosis as risk factors for a post-prostatectomy-incontinence. This paper shows a longer follow-up (95 months) and a larger patient population $(\mathrm{n}=1144)$, but is based on a comparable oncological cohort [21].

Here a multivariate analysis including blood loss, patient's age and disease-state could not identify a risk factor for post-prostatectomy incontinence (s. 4.1.2).

\subsubsection{Status of continence regarding age}

The status of continence in our study population after radical retropubic prostatectomy did not differ significantly in patients younger and older than 70 years of age. Even the early and late status of continence did not show any significant differences. Nevertheless, it was noteworthy that patients suffering from PPI out of the older patient's group showed more urine loss in the ICS $24 \mathrm{~h}$ pad test.

Another group recently reported comparable results: This investigation found, that older patients reached though delayed a status of continence, but that age was no risk factor for a remaining incontinence. This could be determined in a multivariate analysis by Majoros $e t$ al. in 2007, which included 166 patients [26].

In comparative tests carried out in our data (Student's t-test) between status of continence and age, no significant difference could be detected ( $\mathrm{p}=0.61$ ).

\subsubsection{Status of continence and stadium of disease}

No valid analysis of the status of continence could be performed with respect to the histologic stage of the disease because of the small study population. The shown trend indicated independence of the continence status and the histologic stadium of disease. This finding coincides with another recent published study. There the status of continence was compared to the expansion of prostate cancer (T2b to T3) after radical retropubic prostatectomy. The authors could not detect a significant difference (this study included 288 patients; [3]). Moreover, work from Ward and colleagues did not find a relation between the status of continence and the postal-surgical tumour stage (pT2 and pT3) [27].

\subsection{Satisfaction of treatment}

Patients felt well informed concerning about prostate cancer therapy (86.5\%). Cosmetic results were satisfying in $(88.1 \%)$. Comparable satisfaction values were found after radiotherapy. The only striking difference to the surgical approach is that fewer patients would undergo radiotherapy again. A possible explanation is that many patients believe themselves "not being operable any more"[27]. Satisfaction questionnaire showed a small number of patients undergoing therapy of erectile dysfunction (24\%). Thus nerve-sparing prostatectomy should be performed whenever oncological possible.

\section{Conclusion}

Patients undergoing retropubic prostatectomy kept a stable QoL and stable body functions in general. Their emotional situation reached a high and stable level after the procedure. Complaints about typical symptoms of prostate cancer (especially urinary symptoms) stayed in a normal range and were independent of age. In our patients older than 70 years of age we found a mild reduction of QoL and a rising problem concerning dyspnoe. Therefore the indication of prostatectomy should be discussed critically concerning comorbidity.

It has to be admit that the study design and sample size is weak to draw general conclusions.

The results of the sexual symptom scores could not be used to draw general conclusions as well because of a match-pairs analysis, which resulted in a different amount of a nerve-sparing prostatectomy.

In conclusion retropubic prostatectomy represents an accepted and reliable procedure. Nevertheless the primary avoidance or therapy of erectile dysfunction should lie in the focus of surgeons.

\section{Additional material}

Additional file 1: Satisfaction questionnaire. Patients attitude towards performed surgery was asked using a self-created questionnaire.

\begin{abstract}
Abbreviations
ASA: American Society of Anesthesiologists physical status score; EORTC: European Organisation for Research and Treatment of Cancer; GHS: Global Health Status; ICS: International Continence Society; PCa: prostate cancer; PPI: Post-prostatectomy-incontinence; PR25: Module of EORTC QLQ-PR25 specialized prostate cancer; PSA: Prostata-spezifisches Antigen; QLQ-C30: validated questionnaire for QoL; QoL: Quality of life; RPX: radical retropubic prostatectomy; Y: Year
\end{abstract}

\section{Authors' contributions}

TD performed interviews, pad tests and draft the manuscript. CM perfomed surgery and helped to draft the manuscript. AG helped in patients 
recruitment. MG performed surgery, designed the study and wrote the manuscript. All authors read and approved the final manuscript.

\section{Competing interests}

The Authors declare that they have no competing interests.

Received: 28 October 2010 Accepted: 2 November 2011 Published: 2 November 2011

\section{References}

1. Jacobsen NE, Moore KN, Estey E, Voaklander D: Open versus laparoscopic radical prostatectomy: a prospective comparison of postoperative urinary incontinence rates. J Urol 2007, 177(2):615-9.

2. Jo Y, Junichi H, Tomohiro F, Yoshinari I, Masato F: Radical prostatectomy versus high-dose rate brachytherapy for prostate cancer: effects on health-related quality of life. BJU Int 2005, 96(1):43-7.

3. Loeb S, Smith ND, Roehl KA, Catalona WJ: Intermediate-term potency, continence, and survival outcomes of radical prostatectomy for clinically high-risk or locally advanced prostate cancer. Urology 2007, 69(6):1170-5.

4. Gacci M, Simonato A, Masieri L, Gore JL, Lanciotti M, Mantella A, Rossetti MA, Serni S, Varca V, Romagnoli A, Ambruosi C, Venzano F, Esposito M, Montanaro T, Carmignani G, Garini M: Urinary and sexual ootcomes in long-term (5+ years) prostate cancer disease free survivors after radical prostatectomy. Health Qual Life Outcomes 2009, 13(7):94.

5. Lev EL, Eller LS, Gejerman G, Lane P, Owen SV, White M, Ngana N: Quality of life of men treated with brachytherapies for prostate cancer. Health Qual Life Outcomes 2004, 15(2):28

6. van Andel G, Bottomley A, Fosså SD, Efficace F, Coens C, Guerif S, Kynaston H, Gontero P, Thalmann G, Akdas A, D'Haese S, Aaronson NK: An international field study of the EORTC QLQ-PR25: a questionnaire for assessing the health-related quality of life of patients with prostate cancer. Eur J Cancer 2008, 44(16):2418-24.

7. Sprangers MA, Cull A, Bjordal K, Groenvold M, Aaronson NK: The European Organization for Research and Treatment of Cancer. Approach to quality of life assessment: guidelines for developing questionnaire modules. EORTC Study Group on Quality of Life. Qual Life Res 2(4):287-95.

8. Aaronson NK, Ahmedzai S, Bergman B, Bullinger M, Cull A, Duez NJ, Filiberti A, Flechtner H, Fleishman SB, de Haes JC: The European Organization for Research and Treatment of Cancer QLQ-C30: a qualityof-life instrument for use in international clinical trials in oncology. $J$ Natl Cancer Inst 1993, 85(5):365-76.

9. Kaasa S, Bjordal K, Aaronson N, Moum T, Wist E, Hagen S, Kvikstad A: The EORTC core quality of life questionnaire (QLQ-C30): validity and reliability when analysed with patients treated with palliative radiotherapy. Eur J Cancer 1995, 31A(13-14):2260-3.

10. Sutherst J, Brown M, Shawer M: Assessing the severity of urinary incontinence in women by weighing perineal pads. Lancet 1981, 1(8230):1128-30.

11. Lips IM, Dehnad H, van Gils CH, Boeken Kruger AE, van der Heide UA, van Vulpen M: High-dose intensity-modulated radiotherapy for prostate cancer using daily fiducial marker-based position verification: acute and late toxicity in 331 patients. Radiat Oncol 2008, 21(3):15.

12. Lips IM, van Gils $C H$, van der Heide UA, Kruger $A E$, van Vulpen M: Healthrelated quality of life 3 years after high-dose intensitymodulatedradiotherapy with gold fiducial marker-based position verification. BJU Int 2009, 103(6):762-7.

13. Nguyen $\mathrm{PL}$, Chen RC, Clark JA, Cormack RA, Loffredo M, McMahon E, Nguyen AU, Suh WW, Tempany CM, D'Amico AV: Patient-reported quality of life after salvage brachytherapy for radio-recurrent prostate cancer: A prospective Phase II study. Brachytherapy 2009, 8(4):345-52.

14. van der Poel HG, de Blok W, Joshi N, van Muilekom E: Preservation of lateral prostatic fascia is associated with urine continence after roboticassisted prostatectomy. Eur Urol 2009, 55(4):892-900.

15. Giberti C, Chiono L, Gallo F, Schenone M, Gastaldi E: Radical retropubic prostatectomy versus brachytherapy for low-risk prostatic cancer: a prospective study. World J Urol 2009, 27(5):607-12

16. Stanford JL, Feng Z, Hamilton AS, Gilliland FD, Stephenson RA, Eley JW, Albertsen PC, Harlan LC, Potosky AL: Urinary and sexual function after radical prostatectomy for clinically localized prostate cancer: the Prostate Cancer Outcomes Study. Jama 283(3):354-60.
17. Montanari E, Del Nero A, Bernardini P, Trinchieri A, Zanetti G, Rocco B: Epidemiology and physiopathology of urinary incontinence after radical prostatectomy. Arch Ital Urol Androl 73(3):121-6.

18. Arredondo SA, Elkin EP, Marr PL, Latini DM, DuChane J, Litwin MS, Carroll PR, CaPSURE Investigators: Impact of comorbidity on health-related quality of life in men undergoing radical prostatectomy: data from CaPSURE. Urology 2006, 67(3):559-65.

19. Jayadevappa R, Chhatre S, Whittington R, Bloom BS, Wein AJ, Malkowicz SB: Health-related quality of life and satisfaction with care among older men treated for prostate cancer with either radical prostatectomy or external beam radiation therapy. BJU Int 2006, 97(5):955-62.

20. Gupta D, Lis CG, Grutsch JF: The relationship between dyspnea and patient satisfaction with quality of life in advanced cancer. Support Care Cancer 2007, 15(5):533-8

21. Sacco E, Prayer-Galetti T, Pinto F, Fracalanza S, Betto G, Pagano F, Artibani W: Urinary incontinence after radical prostatectomy: incidence by definition, risk factors and temporal trend in a large series with a long-term follow-up. BJU Int 97(6):1234-41.

22. Takenaka A, Soga H, Kurahashi T, Miyake H, Tanaka K, Fujisawa M: Early recovery of urinary continence after laparoscopic versus retropubic radical prostatectomy: evaluation of preoperative erectile function and nerve-sparing procedure as predictors. Int Urol Nephrol 41(3):587-93.

23. Tobía I, González MS, Martínez P, Tejerizo JC, Gueglio G, Damia O, Martí MI, Giudice CA: Randomized study on urinary continence after radical prostatectomy with previous kinesic perineal physiotherapy. Arch Esp Urol 61(7):793-8.

24. McCammon KA, Kolm P, Main B, Schellhammer PF: Comparative quality-of life analysis after radical prostatectomy or external beam radiation for localized prostate cancer. Urology 54(3):509-16.

25. Majoros A, Bach D, Keszthelyi A, Hamvas A, Mayer P, Riesz P, Seidl E, Romics I: Analysis of risk factors for urinary incontinence after radical prostatectomy. Urol Int 78(3):202-7.

26. Ward JF, Slezak JM, Blute ML, Bergstralh EJ, Zincke H: Radical prostatectomy for clinically advanced (cT3) prostate cancer since the advent of prostate-specific antigen testing: 15-year outcome. BJU Int 95(6):751-6.

27. Sanda MG, Dunn RL, Michalski J, Sandler HM, Northouse L, Hembroff L, Lin X, Greenfield TK, Litwin MS, Saigal CS, Mahadevan A, Klein E, Kibel A, Pisters LL, Kuban D, Kaplan I, Wood D, Ciezki J, Shah N, Wei JT: Quality of life and satisfaction with outcome among prostate-cancer survivors. $N$ Engl J Med 358(12):1250-61.

doi:10.1186/1477-7525-9-93

Cite this article as: Bach et al:: Quality of life of patients after retropubic prostatectomy - Pre- and postoperative scores of the EORTC QLQ-C30 and QLQ-PR25. Health and Quality of Life Outcomes 2011 9:93.

\section{Submit your next manuscript to BioMed Central and take full advantage of:}

- Convenient online submission

- Thorough peer review

- No space constraints or color figure charges

- Immediate publication on acceptance

- Inclusion in PubMed, CAS, Scopus and Google Scholar

- Research which is freely available for redistribution 